\title{
Para além de vida e morte: Nietzsche, Freud e a pulsão de poder absoluto
} Beyond life and death: Nietzsche, Freud and the absolute power drive

\section{Diogo Barros Bogéa*}

Resumo: Tentativa de estabelecer um monismo pulsional a partir do conceito nietzschiano de vontade de poder e o conceito freudiano de princípio de prazer. Nossa intenção é unificá-los na ideia de uma pulsão existencial originária, presente e efetivamente atuante em todos os processos existenciais - a pulsão de poder absoluto.

Palavras-chave: Nietzsche; Freud; Vontade de poder; Princípio de prazer; Pulsão

Abstract: Attempt to establish an instinctual monism from the Nietzschian concept of will to power and the Freudian concept of pleasure principle. Our intention is to unify them on the idea of an existential originary drive: the absolute power drive.

Keywords: Nietzsche; Freud; Will to power; Pleasure principle; Drive

\section{Considerações iniciais}

As aproximações possíveis entre Freud e Nietzsche constituem um riquíssimo campo de investigação que tem sido bem explorado - embora ainda de maneira insuficiente - por diversos pesquisadores das áreas de Filosofia e Psicanálise. Apenas para citar dois exemplos já consagrados, temos Nietzsche e Freud - eterno retorno e compulsão à repetição, de Rogério Miranda de Almeida e Freud e Nietzsche - semelhanças e dessemelhanças, de Paul-Laurent Assoun. Gostaríamos de fornecer nossa contribuição neste artigo, procurando estabelecer aproximações e possibilidades de articulação entre o conceito nietzschiano de vontade de poder e o conceito freudiano de princípio de prazer, tentando encaminhar a possibilidade de se pensar um "monismo pulsional" para além da dualidade fundamental estabelecida por Freud entre "vida" e "morte".

Para tanto, este trabalho propõe operar uma dupla releitura, que é também uma dupla ressignificação: por um lado, com base no conceito psicanalítico de pulsão, faremos uma releitura psicanalítica do conceito nietzschiano de vontade de poder - abrindo mão, de certa forma, da pretensão de "fidelidade" ao pensamento de Nietzsche (se bem que, em se tratando de Nietzsche, caberia investigar se as "traições" não acabam sendo mais "fiéis" ao seu pensamento do que as pretensões de estrita fidelidade). Por outro lado, feito esse

* Professor de Filosofia e Psicanálise na Faculdade de Educação da Universidade do Estado do Rio de Janeiro, Rio de Janeiro, RJ. E-mail: diogobogeaa@hotmail.com ORCID: https://orcid.org/0000-0001-5862-819X 
primeiro movimento, utilizaremos a noção de vontade de poder daí resultante para reler e ressignificar a teoria pulsional de Freud em direção a um monismo pulsional.

Nossa referência fundamental nesse artigo é a teoria pulsional de Freud. Assim, iniciaremos com uma breve apresentação do conceito nietzschiano de vontade de poder, sem nos deter nas suas múltiplas possibilidades de interpretação, mas apenas encaminhando uma apresentação geral que nos permitirá repensar a teoria pulsional de Freud para além do dualismo "vida" e "morte".

\section{A vontade de poder}

Herdeiro da metafísica da vontade de Schopenhauer, Nietzsche acrescenta um complemento à vontade - o poder. Onde Schopenhauer via impulso cego, ou vontade de viver, Nietzsche propõe a vontade de poder.

Minha tese é a de que, até agora, a vontade da psicologia é uma injustificável generalização, que não há absolutamente essa vontade, que em vez de conceber a configuração de uma determinada vontade em muitas formas, eliminou-se o caráter da vontade, à medida que se subtraiu o conteúdo, o 'para onde', e esse é o caso, no mais alto grau, em Schopenhauer: o que ele chama de 'vontade' é uma palavra vazia. Trata-se ainda menos de uma 'vontade de vida': pois a vida é apenas um caso isolado da vontade de poder ${ }^{1 ; 2}$.

Poder, aqui, como complemento da vontade não trata de poder político, econômico, físico, etc., sendo estas apenas formas modais, locais, particulares de realização de um conceito muito maior, universal. Poder é simplesmente dominação, acumulação, expansão, superação, mando, atividade, efetivação, em qualquer sentido que se possa imaginar.

A primeira aparição do conceito "vontade de poder" na obra de Nietzsche ocorre em Assim falava Zaratustra, no capítulo "Dos mil e um fins”, em relação à "criação de valores” pelos povos. Os valores de um povo expressam a "voz de sua vontade de poder": "Sobre

\footnotetext{
${ }^{1}$ Utilizaremos aqui como referência para os fragmentos póstumos de Nietzsche, a coleção de fragmentos póstumos publicada no Brasil pela Editora Contraponto em 2008, com tradução de Marcos Fernandes e Francisco de Moraes, cuja referência, como informam os tradutores na página 17, é a já clássica e "oficial" Kritische Studienausgabe editada por Giorgio Colli e Mazzino Montinari. Nunca é demais advertir ao leitor que $A$ vontade de poder não é uma obra de Nietzsche, mas uma coleção de fragmentos póstumos editada por sua irmã Elizabeth Forster-Nietzsche e seu amigo Peter Gast. Não tratamos, portanto, os fragmentos aqui citados como "parte" de uma "obra", mas como fragmentos isolados artificialmente reunidos e publicados postumamente por terceiros.
}

${ }^{2}$ NIETZSCHE, $A$ vontade de poder, p. 351 
cada povo está suspenso um quadro de bens. É o quadro, se vê, de suas vitórias sobre si mesmo; é a voz de sua vontade de poder"3.

Já no capítulo "Da vitória sobre si próprio”, Zaratustra dirige-se aos sábios insignes “Chamais 'vontade de verdade', sábios insignes, o que vos impele e vos excita?”. E o próprio Zaratustra responde:

Vontade de tornar concebível tudo o que existe, assim chamo, eu, vossa vontade.

Primeiro, quereis tornar pensável tudo o que existe porque duvidais, com justa desconfiança, que pensável já o seja.

Mas tudo o que existe deve também se adaptar e se curvar! Assim o quer vossa vontade. Que tudo o que existe se humilhe e se submeta ao espírito como seu espelho e sua imagem

É essa toda a vossa vontade, sábios insignes, uma vontade de poder e mesmo quando falais do bem e do mal e das apreciações de valores. (...)

Sobre o rio do futuro, pusestes vossa vontade e vossos valores. Uma velha vontade de poder, isso é o que o povo me revela, aquilo que o povo considera bom e mau.

Fostes vós, os mais sábios, que instalastes esses passageiros nesse barquinho e lhes destes pompa e nomes suntuosos, vós mesmos e vossa vontade dominadora ${ }^{5}$.

Assim como em "Da vitória sobre si próprio", o conceito aparece como uma espécie de "revelação" que a própria vida lhe confia em segredo, uma vez que ele "penetra" "no próprio coração da vida e até as raízes do seu coração": "Onde quer que encontrasse o que é vivo, encontrei vontade de poder" ${ }^{6}$. E é a própria vida que confia a Zaratustra seu segredo: "eu sou aquela que deve sempre superar-se a si mesma"”.

Podemos notar que já há entre esses dois capítulos uma ampliação da abrangência do conceito de um nível estritamente "antropológico" para um nível "orgânico". Mas essa não é ainda a formulação definitiva do conceito. No aforismo 36 de Além do Bem e do Mal Nietzsche parte da hipótese de que nada de real nos seja dado que não o mundo instintivo de nossos desejos e paixões e prossegue com a seguinte especulação: "não é lícito fazer a tentativa e colocar a questão de se isso que é dado não bastaria para compreender, a partir do que lhe é igual, também o chamado mundo mecânico (ou 'material')?" seria, então, dotado de um mundo pulsional da mesma ordem daquele que experimentamos

3 NIETZSCHE, Assim falava Zaratustra, p. 58

$4 \mathrm{ZA}$, Da vitória sobre si próprio

5 NIETZSCHE, Assim falava Zaratustra, p. 106

6 NIETZSCHE, Assim falava Zaratustra, p. 107

7 NIETZSCHE, Assim falava Zaratustra, p. 107

${ }^{8}$ NIETZSCHE, Além do bem e do mal, p. 39 
em nós, mas simplificado, primitivo. Haveria no universo uma espécie de impulso original que constituiria um protótipo dos nossos desejos e paixões, um impulso primordial que se manifesta posteriormente dividido em funções especializadas na vida orgânica. Trata-se de pensar o mundo possuindo uma instância

Da mesma ordem de realidade que têm nossos afetos, - como uma forma mais primitiva do mundo dos afetos, na qual ainda esteja encerrado em poderosa unidade tudo o que então se ramifica e se configura no processo orgânico (e também se atenua e se debilita, como é razoável), como uma espécie de vida instintiva, em que todas as funções orgânicas, com auto regulação, assimilação, nutrição, eliminação, metabolismo, se acham sinteticamente ligadas umas às outras - como uma forma prévia da vida?

Chegamos, então, à hipótese de que "em toda parte onde se reconhecem 'efeitos', vontade atua sobre vontade - e de que todo acontecer mecânico, na medida em que nele age uma força, é justamente força de vontade, efeito da vontade” ${ }^{10}$. E da mesma maneira como toda a multiplicidade de vontades, paixões e instintos em nós, bem como todas as funções orgânicas podem ser reduzidas a uma única vontade primordial - a vontade de poder - "então se obteria o direito de definir toda força atuante, inequivocamente, como vontade de poder” (BM, § 36) ${ }^{11}$. É isso que leva Nietzsche a afirmar, finalmente, que: “O mundo visto de dentro, o mundo definido e designado conforme o seu 'caráter inteligível' seria justamente 'vontade de poder', e nada mais" ${ }^{12}$. Com isso, mitiga-se a fronteira entre vivo e não-vivo, entre orgânico e inorgânico. A vontade de poder já não se restringe aos humanos e aos povos, nem também somente aos seres vivos. Tendo seu campo de atuação definitivamente ampliado, aplica-se agora a tudo o que existe. A vida passa então a ser concebida como um caso particular da vontade de poder, inserida num processo muito maior, que, no limite, abrange a totalidade da existência.

Assim, a vontade de poder passa a ser compreendida como princípio desejante único que impulsiona em um nível mais fundamental todas as forças físicas, dinâmicas ou psíquicas: “Toda força pulsante é vontade de poder, (...) não há nenhuma força física, dinâmica ou psíquica além daquela"13. O próprio mundo é compreendido como um grande “campo de forças". A vontade de poder é o que determina o caráter da força, seu sentido, sua direção. Toda força quer dominar todas as outras, acumular e expandir seu poder até o limite, superar a si mesma. A vontade de poder é o impulso intrínseco à força, a todas as

\footnotetext{
${ }^{9}$ NIETZSCHE, Além do bem e do mal, p. 40

${ }^{10}$ NIETZSCHE, Além do bem e do mal, p. 40

${ }^{11}$ NIETZSCHE, Além do bem e do mal, p. 40

${ }^{12}$ NIETZSCHE, Além do bem e do mal, p. 40

${ }^{13}$ NIETZSCHE, $A$ vontade de poder, p. 349
} 
forças. Intrinsecamente impulsionadas pela vontade de poder, as forças lutam entre si, e estabelecem relações multiniveladas de dominações e alianças:

[...] cada corpo específico anseia por tornar-se senhor de todo espaço, por estender sua força (-sua vontade de poder:) e repelir tudo que obsta à sua expansão. Mas ele se depara continuamente com o mesmo ansiar de outros corpos e termina por arranjar-se ('unificar'-se) com aqueles que lhes são aparentados o bastante: - assim eles conspiram, então, juntos, pelo poder. $\mathrm{E}$ o processo segue adiante[... $]^{14}$.

A força não é uma "coisa”, não é um “átomo”, não é uma unidade fechada dada a priori. Cada força é resultado do entrelaçamento de incontáveis outras forças. Há "quantidades dinâmicas, em uma proporção de tensão em relação a todas as outras quantidades dinâmicas: seu ser consiste em sua proporção de relação a todas as outras quantidades, em seu 'atuar' sobre as mesmas"15. A força não tem um "ser" constituído a priori. Ela se dá como efeito das tensões, das relações de poder entre outras forças. Uma vez constituída, está automaticamente inserida no campo das relações entre forças e já é um poder de atuação efetivo sobre todas as outras. Um "corpo específico" nada mais é que o resultado de uma combinação de incontáveis forças. Então, podemos compreender o mundo como uma rede dinâmica de forças de todas as ordens, impulsionada em todos os níveis pela vontade de poder. Forças físicas, químicas, biológicas, psíquicas, sociais, culturais, emocionais, num conflito permanente por poder, entrelaçam-se numa rede complexa e dão origem, assim, a diversas configurações - células, tecidos, órgãos, animais, pessoas, coisas, sociedades, ideias, plantas, pedras, etc. No que emerge, uma configuração resultante da rede de forças, passa a contar imediatamente como força em jogo, exercendo seu poder sobre todas as outras, agindo e resistindo sobre todas as outras, gerando novas configurações.

Sendo a vontade de poder o impulso intrínseco a tudo o que existe, o humano, enquanto configuração de forças existente, não poderia escapar à sua determinação. Todos os desejos, instintos, impulsos e pulsões humanos são, para Nietzsche, manifestações da vontade de poder. "A vontade de poder é a forma de afeto primitiva, todos os outros afetos são apenas configurações suas" ${ }^{16}$. "No animal, é possível derivar da vontade de poder todas as suas pulsões" ${ }^{17}$. Deveríamos ousar considerar a psicologia "como morfologia e teoria da evolução da vontade de poder" ${ }^{18}$. A acumulação e a expansão de poder são os únicos critérios de ação e reação segundo a lógica da vontade de poder.

\footnotetext{
${ }^{14}$ NIETZSCHE, $A$ vontade de poder, p. 325

${ }^{15}$ NIETZSCHE, $A$ vontade de poder, p. 324

${ }^{16}$ NIETZSCHE, $A$ vontade de poder, p. 348

${ }^{17}$ NIETZSCHE, $A$ vontade de poder, p. 319

${ }^{18}$ NIETZSCHE, Além do bem e do mal, p. 27
} 


\section{As pulsões de Freud}

Como possivelmente conciliar, então, o monismo desejante de Nietzsche, com os dualismos pulsionais de Freud - concentrados num primeiro momento na oposição entre pulsões sexuais e pulsões do ego e na fase final de sua produção teórica em pulsões de morte e pulsões de vida? Acreditamos que a resposta se encontra em outro conceito freudiano: o princípio de prazer.

No artigo metapsicológico Os instintos ${ }^{19}$ [pulsões] e suas vicissitudes, texto de 1915, Freud se propõe a organizar suas formulações teóricas acerca do "conceito básico (...), que no momento ainda é algo obscuro", mas que é "indispensável”" à compreensão da psicanálise: o conceito de pulsão. Uma pulsão é, por definição, "um estímulo aplicado à mente". Um estímulo que se distingue dos outros estímulos, advindos do exterior, porque parte “de dentro do próprio organismo". Enquanto os estímulos exteriores chocam-se com o aparelho mental num impacto único, gerando em consequência uma reação de simples fuga motora, uma pulsão, "por outro lado, jamais atua como uma força que imprime um impacto momentâneo, mas sempre como um impacto constante". Além disso, por provir de dentro do organismo, "não há como fugir dele" ${ }^{21}$. Uma pulsão, portanto, é, até aqui, uma força constante, inescapável e necessária. "O melhor termo para caracterizar um estímulo instintual [pulsional] seria 'necessidade'. O que elimina uma necessidade é a 'satisfação'”. O que só pode ser alcançado "por uma alteração apropriada da fonte interna de estimulação"22.

Freud define a pulsão como "um conceito situado na fronteira entre o mental e o somático"23. Em nossa interpretação, esta classificação da pulsão como conceito de fronteira, se dá justamente pelo caráter estranho às classificações habituais, desta espécie de "instância desejante" promovida ao primeiro plano por Schopenhauer. Seria mais ou menos como o conceito de "vontade de poder", ou de "força" em Nietzsche: algo que não é nem físico, nem mental, nem material, nem imaterial, mas que atravessa ambos os campos e os constitui.

A pulsão é dotada de quatro características básicas, a saber: pressão, alvo, objeto e fonte. A pressão é "a quantidade de força ou a medida de exigência de trabalho que ela representa". Trata-se de uma característica "comum a todos os instintos [pulsões]" que "é, de fato, sua própria essência”" ${ }^{4}$. O alvo de uma pulsão “é sempre satisfação, que só pode ser

\footnotetext{
${ }^{19}$ A edição que utilizamos optou por traduzir trieb por “instinto”. É um problema já bastante conhecido e suficientemente discutido. Incluiremos "pulsão" entre colchetes a cada vez que houver uma tradução de trieb por "instinto"

${ }^{20}$ FREUD, Os instintos e suas vicissitudes, pp. 137-138

${ }^{21}$ FREUD, Os instintos e suas vicissitudes, p. 138

${ }^{22}$ FREUD, Os instintos e suas vicissitudes, p. 139

${ }^{23}$ FREUD, Os instintos e suas vicissitudes, p. 142

${ }^{24}$ FREUD, Os instintos e suas vicissitudes, p. 142
} 
obtida eliminando-se o estado de estimulação na fonte”. É possível, no entanto, que, embora o alvo permaneça o mesmo, uma pulsão possa percorrer diversos caminhos diferentes que a levem ao mesmo objetivo. Pode mesmo acontecer que uma pulsão tenha "várias finalidades mais próximas ou intermediárias, que são combinadas umas com as outras”. Há ainda o caso de pulsões “inibidas em sua finalidade”, quando a pulsão, por alguma razão, não pode chegar à satisfação completa, sendo inibida ou defletida, o que ocasiona apenas uma "satisfação parcial". O objeto da pulsão é "a coisa em relação à qual ou através da qual a pulsão é capaz de atingir sua finalidade”. O objeto é o que há de mais variável, não estando realmente ligado estritamente a uma pulsão, mas apenas servindo aqui-agora para sua satisfação. É comum que a pulsão troque de objeto muitas vezes ao longo de seu percurso e um só objeto pode ser momentaneamente conveniente a mais de uma pulsão. Por fim, a fonte é "o processo somático que ocorre num órgão ou parte do corpo, e cujo estímulo é representado na vida mental” ${ }^{25}$ por uma pulsão.

Neste momento do desenvolvimento de sua obra, Freud classifica as pulsões em dois grandes grupos: as pulsões do ego, ou auto preservativas, e as pulsões sexuais. As pulsões do ego abrangem tudo o que diz respeito à conservação do indivíduo. Já das pulsões sexuais (nesta tradução, instintos sexuais), diz-se o seguinte:

São numerosos, emanam de grande variedade de fontes orgânicas, atuam em princípio independentemente um da outro e só alcançam uma síntese mais ou menos completa em uma etapa posterior. A finalidade pela qual cada um deles luta é a consecução do 'prazer do órgão', somente quando a síntese é alcançada é que eles entram a serviço da função reprodutora, tornando-se então identificáveis, de modo geral, como instintos [pulsões] sexuais. Logo que surgem, estão ligados aos instintos [pulsões] da auto preservação, dos quais só gradativamente se separam ${ }^{26}$.

Além disso, as pulsões sexuais podem trocar mais facilmente de objeto, o que propicia a capacidade de desempenhar tarefas bem diversas do seu objetivo original.

Esta é a primeira dualidade fundamental da teoria das pulsões, que as divide em grandes grupos opostos: as pulsões do ego e as pulsões sexuais. No entanto, a descoberta de que o ego é capaz de fazer - e faz - de si mesmo um objeto sexual, investindo grandes cargas libidinais em si mesmo - o que ocorre no narcisismo -, desarruma esta dualidade fundamental e leva Freud a repensar a teoria das pulsões.

A libido que assim se alojara no ego foi descrita como 'narcisista'. Essa libido narcisista era também, naturalmente, uma manifestação da força do instinto [pulsão] sexual, no sentido analítico destas palavras, e necessariamente tinha de ser identificada com os instintos [pulsões] de

\footnotetext{
${ }^{25}$ FREUD, Os instintos e suas vicissitudes, p. 143

${ }^{26}$ FREUD, Os instintos e suas vicissitudes, p. 146
} 
auto conservação', cuja existência fora reconhecida desde o início. Assim, a oposição original entre os instintos [pulsões] do ego e os instintos [pulsões] sexuais mostrou-se inapropriada ${ }^{27}$.

Em 1920, em Além do Princípio do Prazer, uma nova dualidade pulsional é formulada. Agora os processos psíquicos se desenrolam sob a pressão das pulsões contrárias de vida e de morte. Partindo da observação deste estranho fenômeno que é a compulsão à repetição, Freud descobre um princípio mais fundamental das pulsões: seu caráter conservador e retrógrado manifesto numa tendência irresistível de retornar sempre a um estado anterior. Aparentemente, os pacientes em estados pós-traumáticos, as crianças, pessoas em análise e mesmo as pessoas comuns em sua vida cotidiana, apresentam a tendência a reviver - em sonhos, brincadeiras, na transferência ou simplesmente na dinâmica de suas relações afetivas - situações passadas desagradáveis, cuja revivescência não poderia lhes proporcionar nenhum tipo de satisfação. Seguindo a trilha da compulsão à repetição, Freud se depara, então, com um atributo universal das pulsões.

Mas como o predicado de ser instintual [pulsional] se relaciona com a compulsão à repetição? Nesse ponto, não podemos fugir à suspeita de que deparamos com a trilha de um atributo universal dos instintos [pulsões] e talvez da vida orgânica em geral que até o presente não foi claramente identificado ou, pelo menos, não explicitamente acentuado. Parece, então, que um instinto [pulsão] é um impulso, inerente à vida orgânica, a restaurar um estado anterior de coisas ${ }^{28}$.

As pulsões não seriam, então, forças progressivas, que impulsionam em direção à acumulação ou à expansão, mas sim "uma expressão da natureza conservadora da substância viva" 29 . Se a mudança e a transformação acontecem, é unicamente pela influência de circunstâncias e estímulos exteriores, que, impedindo que a substância viva se conserve exatamente da forma como está, produz nela modificações que, por sua vez, serão armazenadas para uma posterior repetição. Essas pulsões, portanto, estão fadadas a "dar uma aparência enganadora de serem forças tendentes à mudança e ao progresso, ao passo que, de fato, estão apenas buscando alcançar um antigo objetivo por caminhos tanto velhos como novos"30.

E qual seria este objetivo? O objetivo inerente a tudo o que é "vivo"? Freud afirma que "estaria em contradição com a natureza conservadora dos instintos [pulsões] que o

\footnotetext{
${ }^{27}$ FREUD, Além do princípio do prazer, p. 72

${ }^{28}$ FREUD, Além do princípio do prazer, pp. 53-54

${ }^{29}$ FREUD, Além do princípio do prazer, p. 54

${ }^{30}$ FREUD, Além do princípio do prazer, p. 55
} 
objetivo da vida fosse um estado de coisas que jamais tivesse sido atingido"31. Pelo contrário, "ele deve ser um estado de coisas antigo, um estado inicial de que a entidade viva, numa ou noutra ocasião se afastou e ao qual se esforça por retornar através dos tortuosos caminhos ao longo dos quais seu desenvolvimento conduz. A conclusão é que, tendo o mundo inorgânico precedido o orgânico, o objetivo de todo ser vivo é retornar ao estado inorgânico, ou, nas palavras de Freud: "o objetivo de toda vida é a morte" 32 . Esta seria a fórmula da pulsão de morte. É interessante notar, que, neste estágio, a pulsão extrapola o âmbito individual e passa a ser um impulso inerente à vida orgânica.

As pulsões de auto conservação passam, por seu turno, a ser meras subordinadas das pulsões fundamentais, de vida e morte. Desempenhariam somente a função de "garantir que o organismo seguirá seu próprio caminho até a morte, e afastar todos os modos possíveis de retornar à existência inorgânica que não sejam os imanentes ao próprio organismo”. Isso porque “o organismo deseja morrer apenas do seu próprio modo. Assim, originalmente, esses guardiães da vida eram também os lacaios da morte" 33 . No entanto, haveria uma força trabalhando no sentido contrário às pulsões de morte: as pulsões de vida, que Freud identifica às pulsões sexuais - responsáveis pela reprodução, expansão e complexificação das formas de vida. Os instintos [pulsões] sexuais

São conservadores no mesmo sentido dos outros instintos [pulsões] porque trazem de volta estados anteriores da substância viva; contudo, são conservadores num grau mais alto, por serem peculiarmente resistentes às influências externas; e são conservadores ainda em outro sentido, por preservarem a própria vida por um longo período. São os verdadeiros instintos [pulsões] de vida ${ }^{34}$.

Esta última dualidade, bem como a fixação do caráter conservador e retrógrado das pulsões serão mantidas por Freud até o fim de sua produção teórica, o que se verifica no capítulo dedicado às pulsões em seu Esboço de psicanálise, escrito quase vinte anos após Além do princípio do prazer. "Embora sejam a suprema causa de toda atividade", as pulsões "são de natureza conservadora; o estado, seja qual for, que um organismo atingiu, dá origem a uma tendência a restabelecer esse estado assim que ele é abandonado". "Depois de muito hesitar e vacilar decidimos presumir a existência de apenas dois instintos [pulsões] básicos, Eros e a pulsão destrutiva”. O objetivo de Eros seria "estabelecer unidades cada vez maiores e assim preservá-las - em resumo, unir" ${ }_{35}$, enquanto caberia à pulsão destrutiva "levar o que é vivo a um estado inorgânico", razão

\footnotetext{
${ }^{31}$ FREUD, Além do princípio do prazer, p. 55

${ }^{32}$ FREUD, Além do princípio do prazer, p. 56

${ }^{33}$ FREUD, Além do princípio do prazer, p. 57

${ }^{34}$ FREUD, Além do princípio do prazer, p. 58

${ }^{35}$ FREUD, Esboço de Psicanálise, p. 173
} 
pela qual é chamada "pulsão de morte" ${ }^{36}$. Ainda no Esboço de psicanálise, Freud reafirma a ideia de que "as pulsões tendem a retornar a um estado anterior", mas libera Eros desta exigência de retroação, visto que "fazê-lo pressuporia que a substância viva foi outrora uma unidade posteriormente desmembrada e que se esforça no sentido da reunião". A combinação e o conflito entre estas duas pulsões fundamentais seriam o próprio motor da vida, atuando em todas as funções biológicas: "Nas funções biológicas, os dois instintos [pulsões] básicos operam um contra o outro ou combinam-se mutuamente. Assim, o ato de comer é uma destruição do objeto com o objetivo final de incorporá-lo” e o próprio ato sexual "é um ato de agressão com o intuito da mais íntima união" 37 .

\section{Uma pulsão de prazer absoluto?}

No entanto, há um elemento que atravessa todas as fases da teoria pulsional, o qual irá nos conduzir em nossa tentativa de encontrar em Freud um monismo pulsional que nos permita aproximá-lo de Nietzsche: o princípio de prazer. No texto de 1911, exclusivamente dedicado à descrição do seu modo de operação - Formulações sobre os dois princípios do funcionamento mental -, Freud reconhece a existência de processos primários do inconsciente e, ao esclarecer quais seriam seus objetivos, elabora a definição básica do princípio do prazer:

O propósito dominante obedecido por estes processos primários é fácil de reconhecer; ele é descrito como o princípio de prazer-desprazer, ou, mais sucintamente, princípio de prazer. Estes processos esforçam-se por alcançar prazer; a atividade psíquica afasta-se de qualquer evento que possa despertar desprazer ${ }^{38}$.

Princípio do prazer seria então aquela tendência fundamental do aparelho psíquico a buscar o prazer e evitar o desprazer.

Mesmo aqui, Freud estabelece uma dualidade, pela introdução de um segundo princípio básico: o princípio de realidade. Este último se encarregaria de levar o aparelho mental a considerar a realidade, as exigências do mundo externo, em seus cálculos de prazer-desprazer. Segundo Freud, quando "o estado de repouso psíquico foi originalmente perturbado pelas exigências peremptórias das necessidades internas", as pulsões, "tudo o que havia sido pensado (desejado) foi simplesmente apresentado de maneira alucinatória” ${ }^{39}$, assim como ainda acontece com nossos sonhos. No entanto, como, por este método, a satisfação esperada não era obtida, "o aparelho psíquico teve de decidir formar

\footnotetext{
${ }^{36}$ FREUD, Esboço de Psicanálise, pp. 173-174

${ }^{37}$ FREUD, Esboço de Psicanálise, p. 174

${ }^{38}$ FREUD, Formulações sobre os dois princípios do funcionamento mental, p. 278

${ }^{39}$ FREUD, Formulaçôes sobre os dois princípios do funcionamento mental, p. 278
} 
uma concepção das circunstâncias reais do mundo externo e empenhar-se por efetuar nelas uma alteração real” ${ }^{40}$. É aí que inicia este novo princípio: o princípio de realidade. Freud afirma ser sinal de crescimento e desenvolvimento psíquico, a eficiente substituição do princípio de prazer pelo princípio de realidade.

Não vemos, entretanto, qualquer contradição entre o princípio de prazer e o princípio de realidade. Se o objetivo do aparelho psíquico é buscar o prazer e evitar o desprazer, a inclusão de cada vez mais circunstâncias da realidade neste cálculo, só vem contribuir para aprimorá-lo, evitando situações desagradáveis que poderiam advir da fruição imediata de algum prazer e otimizando as possibilidades de satisfação. O cálculo, de toda forma, permanece o mesmo, de modo que cada ser existente atinge o máximo de prazer possível a cada instante tendo em conta as circunstâncias em jogo em cada momento. O próprio Freud chega a perceber que não há contradição radical entre os princípios:

Tal como o ego-prazer nada pode fazer a não ser querer, trabalhar para produzir prazer e evitar o desprazer, assim o ego-realidade nada necessita fazer a não ser lutar pelo que é útil e resguardar-se contra danos. $\mathrm{Na}$ realidade, a substituição do princípio de prazer pelo princípio de realidade não implica a deposição daquele, mas apenas sua proteção. Um prazer momentâneo, incerto quanto a seus resultados, é abandonado, mas apenas a fim de ganhar mais tarde, ao longo do novo caminho, um prazer seguro ${ }^{41}$.

A economia nos fornece, talvez, o melhor exemplo disso, visto que dispomos de uma cota determinada de recursos por um certo período e temos de administrá-la a fim de suprir nossas necessidades básicas, podendo gastar o excedente imediatamente na satisfação imediata de algum prazer ou economizá-lo a fim de realizar um prazer maior no futuro. Por isso mesmo a expressão "economia psíquica" ou "economia pulsional" é tão frequentemente utilizada. É este mesmíssimo cálculo - embora possamos discutir quanto à sua eficácia neste caso específico - que, como bem assinala Freud, deu origem à "doutrina da recompensa noutra vida pela renúncia - voluntária ou forçada - dos prazeres terrenos" ${ }^{42}$, tão bem explorada pelas religiões.

O princípio de realidade atuaria mais, então, como um agente do princípio de prazer, de tal maneira que poderíamos mesmo abrir mão dele enquanto conceito, e manter apenas o princípio de prazer como atuante no aparelho psíquico, levando em conta que este cálculo - buscar prazer e evitar desprazer - não tem porque não incluir em si mesmo a consideração dos fatores externos, das circunstâncias de todas as ordens - físicas, biológicas, políticas, afetivas, sociais, culturais, etc - em seu processo de efetivação.

\footnotetext{
${ }^{40}$ FREUD, Formulações sobre os dois princípios do funcionamento mental, pp. 278-279

${ }^{41}$ FREUD, Formulações sobre os dois princípios do funcionamento mental, p. 283

${ }^{42}$ FREUD, Formulações sobre os dois princípios do funcionamento mental, p. 283
} 
Em Os instintos [pulsões] e suas vicissitudes, o princípio de prazer aparece associado a uma exigência fisiológica fundamental do sistema nervoso, que "tem por função livrar-se dos estímulos que lhe chegam, ou reduzi-los ao nível mais baixo possível; ou que, caso isso fosse viável, se manteria numa condição inteiramente não estimulada" ${ }^{43}$. Dessa maneira, um aumento de estímulos seria o responsável por uma sensação de desprazer, enquanto uma redução dos estímulos proporcionaria uma sensação de prazer. Nas palavras de Freud: "os sentimentos desagradáveis estão ligados a um aumento e os sentimentos agradáveis a uma diminuição do estímulo" ${ }^{44}$. É seguindo este mesmo princípio que, sendo a pulsão uma determinada quantidade de estímulo, ela traz consigo, como único alvo, a exigência de satisfação, ou seja, de cessação da estimulação psíquica que representa. "Visto que todos os impulsos instintuais [pulsionais] têm os sistemas inconscientes como seu ponto de impacto, quase não constitui novidade dizer que eles obedecem ao processo primário" 45 .

Logo a primeira frase de Além do princípio de prazer já é a seguinte:

$\mathrm{Na}$ teoria da psicanálise não hesitamos em supor que o curso tomado pelos eventos mentais está automaticamente regulado pelo princípio de prazer, ou seja, acreditamos que o curso desses eventos é invariavelmente colocado em movimento por uma tensão desagradável e que toma uma direção tal, que seu resultado final coincide com uma redução dessa tensão, isto é, com uma evitação de desprazer ou uma produção de prazer ${ }^{46}$.

E, logo em seguida, é reafirmada a estrita correspondência entre o princípio de prazer e o chamado princípio de constância:

O aparelho mental se esforça por manter a quantidade de excitação nele presente tão baixa quanto possível ou, pelo menos, por mantê-la constante. Essa última hipótese constitui apenas outra maneira de enunciar o princípio de prazer, porque, se o trabalho do aparelho mental se dirige no sentido de manter baixa a quantidade de excitação, então qualquer coisa que seja calculada para aumentar essa quantidade está destinada a ser sentida como adversa ao funcionamento do aparelho, ou seja, como desagradável. O princípio de prazer decorre do princípio da constância ${ }^{47}$.

Mas, aqui, a dominância do princípio do prazer é questionada por Freud, visto que, no curso dos processos mentais, experimentamos diversas sensações desagradáveis que nem sempre resultam em prazer. O máximo que se pode afirmar, então, “é que existe na

\footnotetext{
${ }^{43}$ FREUD, Os instintos e suas vicissitudes, p. 140

${ }^{44}$ FREUD, Os instintos e suas vicissitudes, p. 141

${ }^{45}$ FREUD, Além do princípio de prazer, p. 51

${ }^{46}$ FREUD, Além do princípio de prazer, p. 17

${ }^{47}$ FREUD, Além do princípio de prazer, p. 19
} 
mente uma forte tendência no sentido do princípio de prazer, embora essa tendência seja contrariada por certas outras forças ou circunstâncias" ${ }^{48}$.

Freud vê na compulsão à repetição, observada na transferência em análise, nas brincadeiras infantis e nos sonhos pós-traumáticos, ou seja, a tendência a reencenar e reviver aspectos desagradáveis e traumáticos do passado, um processo que foge completamente ao domínio do princípio do prazer e que, portanto, seria anterior a ele, mais originário, mais fundamental - daí o título da obra ser “Além” do princípio de prazer.

Nenhuma dessas coisas pode ter produzido prazer no passado, e poder-se-ia supor que causariam menos desprazer hoje se emergissem como lembranças ou sonhos, em vez de assumirem a forma de experiências novas. Constituem, naturalmente, as atividades das pulsões destinadas a levar à satisfação, mas nenhuma lição foi aprendida da antiga experiência de que essas atividades, ao contrário, conduziriam apenas ao desprazer. A despeito disso, são repetidas, sob a pressão de uma compulsão ${ }^{49}$.

Isso faria da compulsão à repetição, justamente um elemento psíquico que "sobrepuja o princípio do prazer" 50 .

Como vimos, foi desta predominância da compulsão à repetição no aparelho psíquico, que Freud deduziu o caráter conservador e mesmo retrógrado das pulsões. E foi esta descoberta, por sua vez, que o levou a elaborar a teoria da pulsão de morte enquanto impulso de todo ser orgânico a retornar a um estado inorgânico anterior. No entanto, não podemos deixar de notar que esta formulação básica da pulsão de morte encontra grande afinidade com aquela do princípio de prazer. Se o princípio de prazer correspondente ao princípio de constância é um esforço no sentido da diminuição dos estímulos do aparelho psíquico, uma tendência no sentido de zerar estes estímulos - ou em outros termos, buscar prazer e evitar desprazer -, a pulsão de morte não deixa de apresentar a mesma exigência de extinção de toda estimulação presente na vida orgânica, ou seja, um impulso de retorno ao inorgânico, a um momento de quietude anterior ao início dos processos de estimulação. O próprio Freud assinala a íntima relação entre a pulsão de morte ao princípio de prazer, nesta mesma passagem em que utiliza a expressão "princípio do Nirvana":

A tendência dominante da vida mental, e, talvez, da vida nervosa em geral, é o esforço para reduzir, para manter constante ou para remover a tensão interna devida aos estímulos (o 'princípio do Nirvana', (para tomar de empréstimo uma expressão de Bárbara Low), tendência que encontra expressão no princípio de prazer, e o reconhecimento deste fato constitui

\footnotetext{
${ }^{48}$ FREUD, Além do princípio de prazer, p. 20

${ }^{49}$ FREUD, Além do princípio de prazer, p. 35

${ }^{50}$ FREUD, Além do princípio de prazer, p. 36
} 
uma de nossas mais fortes razões para acreditar na existência dos instintos [pulsões] de morte ${ }^{51}$.

E novamente nesta outra passagem:

O princípio de prazer, então, é uma tendência que opera a serviço de uma função, cuja missão é libertar inteiramente o aparelho mental de excitações, conservar a quantidade de excitação constante nele, ou mantê-la tão baixa quanto possível. (...) a função estaria assim relacionada com o esforço mais fundamental de toda substância viva: o retorno à quiescência do mundo inorgânico ${ }^{52}$.

A tendência a retornar a um estado anterior, então, presente na compulsão à repetição e que encontra sua expressão máxima na pulsão de morte não são de maneira alguma contrárias ao princípio de prazer. Pelo contrário, podem tranquilamente ser compreendidas como expressões suas.

As pulsões de vida - as pulsões sexuais -, por outro lado, não constituem nenhuma objeção ao princípio de prazer, como o próprio Freud também reconhece: “Todos nós já experimentamos como o maior prazer por nós atingível, o do ato sexual, acha-se associado à extinção momentânea altamente intensificada" ${ }^{53}$. E embora eles estejam com frequência "surgindo como rompedores da paz e constantemente produzindo tensões”, proporcionam também um "alívio" que "é sentido como prazer" ${ }_{54}$.

O princípio de prazer aparece, então, em cada momento do desenvolvimento da teoria das pulsões, como elemento primordial, único, que dirige o funcionamento do aparelho mental. Ora, se a tendência do princípio do prazer é zerar todos os estímulos, eliminar o desprazer, sua empresa constitui uma tarefa impossível. Todo o tempo somos bombardeados com uma incrível abundância de estímulos externos e, por outro lado, e de maneira ainda mais grave, porque sem possibilidade de fuga, os estímulos internos, as pulsões, nos perturbam e nos inquietam de tal maneira que nunca nos encontramos plenamente livres de estimulações. As fontes de sofrimento estão em toda parte e para atingir a mais tênue satisfação com a realização do mais despretensioso de nossos desejos, temos de enfrentar uma vasta gama de circunstâncias de todas as ordens que se colocam em nosso caminho como obstáculos.

No entanto, há algo aqui para o que gostaríamos de chamar especialmente a atenção: qual é o principal obstáculo à realização do princípio do prazer? É a sua própria existência enquanto estímulo intrínseco e constante que não cessa de exigir para si uma satisfação absoluta que nunca comparece. Enquanto estímulo interno que exerce uma

\footnotetext{
${ }^{51}$ FREUD, Além do princípio de prazer, p. 76

${ }^{52}$ FREUD, Além do princípio de prazer, p. 83

${ }^{53}$ FREUD, Além do princípio de prazer, p. 83

${ }^{54}$ FREUD, Além do princípio de prazer, p. 85
} 
pressão constante, o princípio de prazer apresenta quase todas as características principais de uma pulsão. Vejamos: Trata-se de um estímulo pulsional interno que exerce uma pressão constante sobre o aparelho psíquico - sendo, então, uma força constante e inescapável. É um processo inconsciente, não dependendo da consciência para existir. Seu alvo é sua própria satisfação. Uma satisfação absoluta, que corresponderia ao gozo de um prazer absoluto. Seu objeto é toda e qualquer coisa que possa lhe proporcionar alguma satisfação. Sendo extremamente variável, mas, alguns podendo permanecer os mesmos por longos períodos de tempo. Só não poderíamos situar em nenhuma parte a sua fonte, uma vez que um estímulo desta natureza, que não possui realização possível, também não pode ter começado em lugar ou tempo algum. Isso nos leva a mais uma importante consideração: A pulsão que estamos procurando descrever, a qual corresponderia ao princípio do prazer, é sempre, necessariamente inibida em sua finalidade, por não possuir qualquer possibilidade de satisfação absoluta. Lança-se aos mais diversos objetos, atingindo somente, a cada vez, uma satisfação parcial. Assim, poderíamos tomar emprestada a formulação de Lacan: "as pulsões, tais como elas se apresentam no processo da realidade psíquica, são pulsões parciais” ${ }^{55}$, para dizer que em relação à exigência de prazer absoluto desta espécie de pulsão fundamental, as pulsões são sempre parciais. E ele também tem razão quando afirma que "o princípio de prazer se caracteriza mesmo por isso que o impossível está ali tão presente que ele jamais é reconhecido como tal”56.

Esta definição da pressão exercida pelo princípio do prazer em Mal-Estar na Civilização vem corroborar nossa hipótese:

O programa de tornar-se feliz, que o princípio do prazer nos impõe não pode ser realizado; contudo, não devemos - na verdade, não podemos abandonar nossos esforços de aproximá-lo da consecução, de uma maneira ou de outra. Caminhos muito diferentes podem ser tomados nessa direção, e podemos conceder prioridades quer ao aspecto positivo do objetivo, obter prazer, quer ao negativo, evitar o desprazer. Nenhum desses caminhos nos leva a tudo o que desejamos ${ }^{57}$.

Assim, o princípio de prazer poderia ser descrito como uma pulsão de prazer absoluto. O objetivo dessa pulsão de prazer absoluto é absolutamente impossível. No entanto, não deixamos jamais de buscar atingi-lo. Não podemos deixar de desejar o prazer absoluto, por mais que, enquanto absolutamente impossível, ele nunca compareça. Mas, como pode ser que o aparelho psíquico tenha chegado algum dia a se empenhar - e permaneça sempre empenhado - num empreendimento de realização impossível?

\footnotetext{
${ }^{55}$ LACAN, Os quatro conceitos fundamentais da psicanálise, p. 172

${ }^{56}$ LACAN, Os quatro conceitos fundamentais da psicanálise, p. 165

${ }^{57}$ FREUD, O mal-estar na civilização, p. 102
} 


\section{A fantasia}

Encontramos a resposta para esta pergunta no próprio Formulação sobre os dois princípios do funcionamento mental. O desejo de prazer absoluto, este objetivo impossível, só pode se sustentar justamente naquela espécie de "atividade do pensamento" que "foi separada; ela foi liberada do teste de realidade e permaneceu subordinada somente ao princípio de prazer" 58 . Esta atividade "é o fantasiar, que começa já nas brincadeiras infantis, e posteriormente, conservada como devaneio, abandona a dependência de objetos reais" 59 . É pela fantasia, e somente pela fantasia, que a pulsão pode projetar em cada investimento sua realização impossível como possível. E é por isso que a satisfação de um desejo não encerra de uma vez o jogo. Em cada satisfação, a pulsão tem de lidar com o fato irremediável de ter gozado apenas uma satisfação parcial, possível, e não a realmente desejada, o prazer absoluto.

Em O Mal-Estar na Civilização, Freud reafirma sua definição de fantasia, da "vida da imaginação": "na época em que o desenvolvimento do senso de realidade se efetuou, essa região foi expressamente isentada das exigências do teste de realidade e posta de lado a fim de realizar desejos difíceis de serem levados a termo" ${ }^{60}$. Mas, a situação neste caso é um pouco mais grave: a imaginação não podia ter sido dominada pelo "teste de realidade", porque ela mesma é intrínseca ao princípio de prazer. Ela, de certa forma, é o que lhe dá sustentação, ou seja, permanece sempre "de lado" a fim de continuar excitando um desejo impossível de ser levado a termo. Com isso chegamos a formular o seguinte: a pulsão de prazer absoluto é intrinsecamente alucinatória, no que concordamos inteiramente com o psicanalista MD Magno:

[...] fora do impulso alucinatório, que costumamos chamar de Pulsão, não é possível pensar uma economia psíquica ou qualquer outra. Começa-se daí e isto já é o bastante para entender nossa loucura, nosso corre-corre atrás do quê? De uma alucinação, que, no entanto, não vai sossegar só porque queremos. A alucinação está lá como (e na) estrutura: a estrutura alucina, empurra, empuxa, impulsiona nesse sentido ${ }^{61}$.

Em Formulação sobre os dois princípios do funcionamento mental Freud marca a passagem entre a fase de satisfação alucinatória do princípio do prazer e a fase posterior, em que o aparelho mental é levado a considerar a realidade e buscar alterá-la de fato. No entanto, em $O$ Mal-Estar na Civilização, vemos que esta passagem nunca aconteceu plenamente, porque não pode ser total. Freud enumera diversas formas diferentes de viver, ou seja, uma série de maneiras comumente adotadas pelas pessoas para atender às

\footnotetext{
${ }^{58}$ FREUD, Formulações sobre os dois princípios do funcionamento mental, p. 281

${ }^{59}$ FREUD, Formulações sobre os dois princípios do funcionamento mental, pp. 281-282

${ }^{60}$ FREUD, O mal-estar na civilização, p. 99

${ }^{61}$ MAGNO, Economia Fundamental, p. 21
} 
exigências incessantes do princípio de prazer. A que mais nos interessará aqui, é aquela que "considera a realidade como a única inimiga e a fonte de todo o sofrimento, com a qual é impossível viver, de maneira que, se quisermos ser de algum modo felizes, temos de romper todas as relações com ela" ${ }^{2}$.

A forma de manifestação mais extremada desta via é "tentar recriar o mundo, em seu lugar construir um outro mundo, no qual os seus aspectos mais insuportáveis sejam eliminados e substituídos por outros mais adequados a nossos próprios desejos” (ib., p. 100). Aquele que procede desta forma, se "não encontra ninguém para ajudá-lo a tornar real o seu delírio”, “torna-se um louco”. Mas, vejamos o seguinte:

Afirma-se, contudo, que cada um de nós se comporta, sob determinado aspecto, como um paranoico, corrige algum aspecto do mundo que lhe é insuportável pela elaboração de um desejo e introduz esse delírio na realidade. Concede-se especial importância ao caso em que a tentativa de obter uma certeza de felicidade e uma proteção contra o sofrimento através de um remodelamento delirante da realidade, é efetuada por um considerável número de pessoas. As religiões da humanidade devem ser classificadas entre os delírios de massa desse tipo. É desnecessário dizer que todo aquele que partilha um delírio jamais o reconhece como tal ${ }^{63}$.

Ora, mas o que é a realidade? Haverá um mundo objetivo, real, totalmente imune aos desejos e fantasias pulsionais? A verdade é que "cada um de nós" se comporta realmente assim. Esta é a única maneira de existir que conhecemos - desejante e alucinatória - e ela dá conta de todas as outras enumeradas por Freud. Aquilo mesmo que chamamos "realidade" não é senão uma rede de circunstâncias desejantes e alucinatórias entrecruzadas, acumuladas umas sobre as outras, cristalizadas em certos pontos, acreditadas, compartilhadas em alguma medida.

Com isso, temos de contestar o caráter "retrógrado" de toda pulsão e nos opor decididamente à afirmação de que "estaria em contradição à natureza das pulsões que o objetivo da vida fosse um estado de coisas que jamais houvesse sido atingido"64. Pelo contrário, nos vemos obrigados a inferir que estaria em contradição à natureza da pulsão de prazer absoluto que seu objetivo fosse algo que já houvesse sido atingido. Nesse caso, teria sido um dia possível, a pulsão teria se realizado e não mais haveria. Se Freud chega a imaginar o mundo inorgânico como objetivo da vida, é apenas porque imagina no mundo orgânico um estado ideal de coisas: um mundo sem qualquer estímulo, que repousa eternamente em paz. Mas não é, absolutamente, o que acontece. Assim como Schopenhauer e Nietzsche já haviam percebido, o mundo inorgânico é também permeado

\footnotetext{
${ }^{62}$ FREUD, O mal-estar na civilização, p. 100

${ }^{63}$ FREUD, $O$ mal-estar na civilização, p. 100

${ }^{64}$ FREUD, Além do princípio de prazer, p. 55
} 
por estímulos, também é impulsionado pela pressão constante da pulsão. E é justamente esta manifestação da pulsão no mundo inorgânico que os físicos procuram descrever com suas "forças" e "leis". Negligenciando a inquietação do mundo inorgânico, Freud absolutiza as noções de "vida" e "morte", vendo-se preso à dualidades "pulsões de vida" x “pulsões de morte”.

Assim, quando Freud estabelece o caráter retrógrado da pulsão e imagina um mundo inorgânico como objeto ideal, como reino da paz absoluta capaz de manter um nível zero de estimulação, está apenas fazendo uma projeção alucinatória do prazer absoluto desejado para um estado de perfeição anterior que nunca houve. Encontramos o mesmo raciocínio em muitas outras esferas: a ideia de que participávamos de um estado anterior de perfeição, do qual por algum motivo fomos afastados e ao qual agora ansiamos por retornar. O mito da queda do paraíso, bem como a ideia de uma época anterior à civilização, em que desfrutávamos da felicidade e da generosidade da natureza são bons exemplos neste sentido. Acontece que desejamos tão intensamente aquilo que não há - o prazer absoluto -, mas que se nos apresenta como fantasia, que chegamos a achar que se trata de alguma coisa que um dia realmente tivemos.

\section{A pulsão de poder absoluto}

De que maneira, poderíamos fazer uma aproximação entre esta concepção de uma pulsão de prazer absoluto e a "vontade de poder" de Nietzsche? Em primeiro lugar, temos de apresentar as críticas nietzschianas à ideia da busca de prazer como objetivo máximo da vida. Segundo Nietzsche, prazer e desprazer são fenômenos secundários, são apenas consequências de uma variação na quantidade de poder do organismo percebida pela consciência. De modo que prazer corresponderia a um aumento e desprazer a uma diminuição do grau de poder obtidos por uma determinada configuração de forças. Nesta passagem, Nietzsche se contrapõe à definição básica do princípio de prazer:

O homem não procura o prazer e não evita o desprazer (...). Prazer e desprazer são meras consequências, meras manifestações acompanhantes o que o homem quer, o que cada mínimo pedaço de um organismo vivo quer é mais poder. No ansiar por isso segue-se tanto prazer como desprazer ${ }^{65}$.

E Nietzsche explica: "Um estado que acompanha um acontecer, e já é um efeito do acontecer, é projetado como 'razão suficiente' do mesmo"66. Na verdade, o prazer apenas acompanha um aumento de poder no sistema e é posteriormente projetado como causa ou como objetivo do movimento que é, em essência, de acumulação e expansão de poder.

\footnotetext{
${ }^{65}$ NIETZSCHE, $A$ vontade de poder, p. 354

${ }^{66}$ NIETZSCHE, $A$ vontade de poder, p. 350
} 
Prazer é, então, apenas a consequência de um aumento de poder. Não se busca, portanto, prazer, mas sim poder. Ainda que possamos pensar o prazer como diminuição dos estímulos atuantes numa configuração de forças, se compreendemos que estes estímulos não são senão manifestações da vontade de poder, esta diminuição da estimulação que resulta em prazer é já consequência de um aumento de poder, enquanto domínio, expansão, crescimento ou acumulação. Prazer e desprazer seriam apenas elementos secundários nesta economia, o que faz da busca pelo poder o verdadeiro processo primário em Nietzsche. Mas, se neste ponto Nietzsche e Freud parecem inconciliáveis, como bem aponta Paul-Laurent Assoun ${ }^{67}$, veremos que resta ainda uma possibilidade de diálogo conceitual entre eles - mais especificamente, entre a pulsão de prazer absoluto que deduzimos do conceito freudiano de princípio de prazer e a "vontade de poder" de Nietzsche.

Aqui cabe uma advertência ao leitor. A leitura da vontade de poder que se encaminhará a seguir é uma releitura psicanalítica do conceito. Uma abordagem, portanto, que não se encontra na obra de Nietzsche e com a qual podemos imaginar que o próprio Nietzsche não concordaria. Ressignificando o conceito de vontade de poder a partir da teoria freudiana das pulsões - assim como afirmamos em relação ao princípio de prazer poderíamos dizer que a vontade de poder possui todas as características de uma pulsão: trata-se de uma força constante, interna - ou melhor, intrínseca -, que exerce uma pressão constante sobre qualquer sistema configurado existente. É, portanto, inescapável e inconsciente, no sentido de que independe da consciência para existir. Seu alvo é sua própria satisfação absoluta - o que corresponderia neste caso ao gozo de um Poder Absoluto. Seu objeto é todo e qualquer objeto existente que lhe possa servir para lhe proporcionar uma satisfação momentânea e prosseguir na direção do seu alvo. Tratam-se de objetos infinitamente variados, podendo alguns permanecerem fixos por longos períodos de tempo. Não é possível, de maneira alguma, determinar a sua fonte, já que uma força intrínseca à existência, como é a vontade de poder, não pode ter se originado em parte alguma, pois isso equivaleria dizer que ela se originou em algum tempo ou lugar “anterior” à existência. E, por fim, temos de concluir da mesma forma, que se trata de uma pulsão inibida em seu alvo, já que poder absoluto é o absolutamente impossível, irrealizável, inatingível, inexistente mesmo. É o que se deseja, é o que não se pode deixar de desejar, por mais que seja um desejo de algo simplesmente impossível de comparecer. Sua existência, enquanto desejo de algo impossível, só pode se sustentar, assim como no caso do princípio de prazer, por aquela estranha faculdade que permaneceu - porque esteve desde sempre - ao seu serviço: a fantasia, que neste ponto, não precisa mais ser compreendida como uma faculdade humana, mas como uma característica própria da

\footnotetext{
${ }^{67}$ ASSOUN, Freud e Nietzsche, p. 163
} 
pulsão. A pulsão existencial é intrinsecamente fantasista, porque vive de fantasiar seu próprio objetivo impossível - o poder absoluto.

Por um lado, é difícil imaginar que Nietzsche concordaria com uma tal interpretação, afinal, ele insiste em marcar sua diferença em relação a Schopenhauer pela recusa decidida em atribuir um "objetivo final", ainda que impossível, para a "vontade". Isto é, Nietzsche nega que a vontade busque um "apaziguamento" último, um "Nirvana", como parece indicar Schopenhauer - se não certamente em todos, mas ao menos em alguns trechos de $O$ mundo como vontade e representação ${ }^{68}$. Nietzsche insiste que a vontade de poder é sempre vontade de "mais poder" e que qualquer fantasia de "poder absoluto" seria um artifício da postura existencial "fraca" e "malograda" que, incapaz de se manter no exercício "ativo" e "alegre" desse movimento de "sempre mais" poder que a vontade impõe, vinga-se da existência fantasiando um "poder absoluto" ilusório de qualquer tipo. A postura "forte" é aquela que insiste no caráter permanentemente aberto e inacabado desse "mais poder", sem qualquer fantasia de "poder absoluto"69. Por outro lado, cabe indagar em que medida essa formulação não leva Nietzsche muitas vezes a personificar essa postura existencial na figura de um humano - ou "além-do-humano” "forte" e "puramente afirmador" e em que medida essa "pura afirmatividade" não poderia constituir ela mesma uma espécie de "ideal” nietzschiano de poder absoluto. Além do mais não deixa de ser pertinente a questão: até que ponto um movimento de "sempre mais poder" escaparia de estar referido a um "poder absoluto" - absolutamente impossível - que se coloca como horizonte último?

A partir de nossa releitura psicanalítica do conceito de vontade de poder, torna-se possível, então, propor a existência de uma pulsão primordial, originária, única, da qual todas as outras forças desejantes do mundo são expressões. Uma única pulsão atuante em todos os processos existenciais: tanto no orgânico quanto no inorgânico, tanto na criação quanto na destruição, tanto na guerra quanto na paz, tanto no movimento quanto no repouso, em toda a beleza e em todo o sombrio, no terrível, no tenebroso, no bem e no mal - em qualquer escala de valores que se possa estabelecer, justamente por ser força constante da criação e da destruição "além de bem e de mal”. Força cósmica atuante em todos os processos da existência, sem “antes”, nem "além”. Um constante estilhaçar-se a si mesma nas multiplicidades de configurações que constituem o mundo, num conflituoso processo de enredamento de forças que nunca começou e nunca terminará. Numa palavra: uma pulsão de poder absoluto.

Assim, nos colocamos em condições de compreender inclusive o estranho fenômeno da compulsão à repetição abordado por Freud. Os exemplos utilizados por Freud em Além

\footnotetext{
${ }^{68} \mathrm{Na}$ seção $§ 68$ por exemplo.

${ }^{69}$ É um tema recorrente na obra de Nietzsche. Algumas formulações bem claras e diretas aparecem por exemplo nas seções $\$ 13$ e $\$ 14$ da terceira dissertação de $A$ genealogia da moral e na seção $\$ 15$ de $O$
} Anticristo. 
do princípio do Prazer são: 1. O jogo elaborado por aquele "menino de um ano e meio" que o autor omite, no texto, se tratar de seu próprio neto. $\mathrm{Na}$ estranha brincadeira, o menino atirava para longe de si um objeto ao mesmo tempo em que gritava algo que foi interpretado por Freud como "fort" ("foi embora"). Quando havia oportunidade de trazer o objeto de volta para junto de si, o menino dizia “da” (“está aqui”). Freud vê na brincadeira do neto a encenação repetitiva de uma experiência de intensa frustração desprazerosa: o afastamento momentâneo da mãe, processado pelo aparelho psíquico como um terrível abandono. Trata-se do primeiro indício apresentado por Freud de uma espécie de "impulso" que, por sua independência e anterioridade, estaria efetivamente "além" do princípio de prazer. A criança

Achava-se numa situação passiva, era dominada pela experiência; repetindo-a, porém, por mais desagradável que fosse, como jogo, assumia papel ativo. Esses esforços podem ser atribuídos a um instinto [pulsão] de dominação [Bemächtigungstrieb] que atuava independentemente de a lembrança em si mesma ser desagradável ou não ${ }^{70}$.

Freud se diz, então, em dúvida, "quanto a saber se o impulso para elaborar na mente alguma experiência de dominação, de modo a tornar-se senhor dela, pode encontrar expressão como um evento primário e independentemente do princípio de prazer"71.

2. O outro exemplo decisivo enunciado por Freud é o da insistente repetição dos sonhos que reencenam situações traumáticas. Pois, que prazer poderia advir da revivescência onírica do trauma? A resposta de Freud revela, uma vez mais, a atuação de uma pulsão de poder operante para além do princípio de prazer. O que caracteriza o trauma é a invasão súbita do psiquismo por uma grande quantidade de estímulo sem que houvesse qualquer preparação prévia. A ansiedade constitui uma espécie de reforço dos sistemas de defesa do aparelho psíquico contra possíveis impactos de estímulos desprazerosos. No trauma, o aparelho psíquico é pego “de surpresa”, por um impacto de intensos estímulos desprazerosos para o qual nenhuma ansiedade prévia nos terá preparado.

Qual poderia ser, então, a função da insistente repetição onírica de experiências traumáticas? Parece impossível atrelá-las a qualquer exigência de "prazer", já que nos fazem reviver justamente experiências exorbitantes de desprazer. Freud responde:

Podemos antes supor que aqui os sonhos estão ajudando a executar outra tarefa, a qual deve ser realizada antes que a dominância do princípio de prazer possa mesmo começar. Esses sonhos esforçam-se por dominar retrospectivamente o estímulo, desenvolvendo a ansiedade cuja omissão constituiu a causa da neurose traumática. Concedem-nos assim a visão de

\footnotetext{
${ }^{70}$ FREUD, Além do princípio de prazer, p. 27

${ }^{71}$ FREUD, Além do princípio de prazer, p. 28
} 
uma função do aparelho mental, visão que, embora não contradiga o princípio de prazer, é sem embargo independente dele, parecendo ser mais primitiva do que o intuito de obter prazer e evitar desprazer ${ }^{72}$.

Os sonhos traumáticos respondem, portanto, a uma exigência de poder. Trata-se da tentativa alucinatória de construir retrospectivamente as defesas necessárias para fazer frente à onda invasora de estímulos desagradáveis que nos atingiram com a experiência traumática. Assim, vemos que "a tarefa de dominar ou sujeitar as excitações, teria precedência, não, na verdade, em oposição ao princípio de prazer, mas independentemente dele e, até certo ponto, desprezando-o"73. Os exemplos de Freud parecem se referir a uma pulsão de domínio, assenhoreamento, controle ou simplesmente poder, mais originária que o "princípio" ou a pulsão "de prazer”. Uma pulsão, consequentemente, mais originária que as pulsões “de vida" e "de morte".

\section{Considerações finais}

Duas tentativas recentes e muito bem-sucedidas de se estabelecer um monismo pulsional universal a partir da teoria das pulsões de Freud, foram empreendidas por André Martins em Pulsão de Morte? e por MD Magno, numa vasta e riquíssima obra que continua em pleno processo de produção.

André Martins, numa competente releitura spinozista de Freud, postula a existência de uma pulsão originária sem representação possível, intrínseca e atuante em todos os processos da existência:

A ideia de uma pulsão originária e sem representação possível, sem mais ser de morte, portanto, nos parece interessante e útil para descrever o fato de que há vida, não mais no sentido de um polo, de uma dicotomia (oscilante ou dialética, que seja), do que se opõe à morte, mas no sentido de uma transformação contínua, de pulsação, de devir. Como força intrínseca e imanente geradora de movimento e vida, anima, mas no sentido de movimento; não no sentido de vida orgânica apenas - sendo esta apenas um dos modos gerados pela pulsão -, e que portanto pulsa tanto no orgânico quanto no inorgânico ${ }^{74}$.

MD Magno, por outro lado, é que nos fornece o modelo conceitual de pulsão aqui esboçado, ao conceber pulsão como desejo de realização impossível, desejo de impossível absoluto, sintetizado na fórmula Haver desejo de não-Haver. Para Magno, a totalidade do que há, ou seja, o Haver existencial como um todo, é intrinsecamente impulsionado por

\footnotetext{
${ }^{72}$ FREUD, Além do princípio de prazer, p. 48

${ }^{73}$ FREUD, Além do princípio de prazer, p. 52

${ }^{74}$ MARTINS, Pulsão de morte?, p. 331
} 
uma força constante que requisita um avessamento impossível, o gozo absolutamente impossível de não-Haver - absolutamente impossível, porque não-Haver, como o próprio nome diz, não há. Mas o não-Haver, o que não há, continua sendo desejado sem cessar, porque a pulsão é intrinsecamente alucinatória: fantasia constantemente seu objetivo. Portanto, não há nenhuma falta originária, nenhum desejo de retorno a algum estado anterior de perfeição que se perdeu. Pelo contrário: a pulsão fantasia aquilo mesmo que ela deseja - não-Haver. Esta é a pulsão fundamental do Haver e de nossa espécie, que é marcada pela capacidade - ou pela condenação mesmo - de replicar o desejo de reviramento impossível do Haver, ou seja, o desejo absolutamente impossível de passar a não-Haver.

Pelo menos em termos da nossa espécie, se não, do universo, há um movimento desejante, um movimento de tesão, que quer o que? Simplesmente sumir! Quer morrer de gozar, quer gozar para sempre, quer um gozo absoluto, último e definitivo! (...)

Todos os tesões que existem por aí são na verdade tesões em algo que é impossível porque simplesmente não existe. Estamos submetidos a um movimento de desejo por algo que jamais vai se oferecer. E tampouco adianta desistir porque sabemos que nunca vai se oferecer, pois a máquina funciona assim. Ela só funciona se quiser o Impossível ${ }^{75}$.

E o processo é necessariamente “alucinatório”, pois “o não-Haver como requerido (...) é alucinado, porque simplesmente não há. O não-Haver (...) só vai comparecer como alucinação"76.

Como se vê, a única contribuição que nosso trabalho pode pretender acrescentar a esta discussão é trazer o conceito nietzschiano de vontade de poder para introduzir o poder como caráter diferencial desta pulsão originária, efetivamente presente e atuante em todos os processos existenciais e determinar seu objetivo absolutamente impossível, seu não-Haver fantasiado e desejado, como poder absoluto. O que nos permitiria falar numa pulsão de poder absoluto para além de vida e morte.

\section{Referências}

ALMEIDA, Rogério Miranda de. Nietzsche e Freud - eterno retorno e compulsão à repetição. São Paulo: Edições Loyola, 2005

ASSOUN, Paul-Laurent. Freud e Nietzsche - semelhanças e dessemelhanças. São Paulo: Brasiliense, 1989

\footnotetext{
${ }^{75}$ MAGNO, A psicanálise, NovaMente, p. 23

${ }^{76}$ MAGNO, Economia Fundamental, p. 21
} 
FREUD, Sigmund. As pulsões e suas vicissitudes, v. 14. In Edição standard brasileira das obras psicológicas completas de Sigmund Freud. Rio de Janeiro: Imago, 1974a

FREUD, Sigmund. O mal-estar na civilização, v. 21. In Edição standard brasileira das obras psicológicas completas de Sigmund Freud. Rio de Janeiro: Imago, 1974b

FREUD, Sigmund. Esboço de psicanálise, v. 23. In Edição standard brasileira das obras psicológicas completas de Sigmund Freud. Rio de Janeiro: Imago, 1975a

FREUD, Sigmund. Formulaçôes sobre os dois princípios do funcionamento mental, v. 12. In Edição standard brasileira das obras psicológicas completas de Sigmund Freud. Rio de Janeiro: Imago. (trabalho original publicado em 1911), 1975b

FREUD, Sigmund. Além do princípio do prazer, v. 18. In Edição standard brasileira das obras psicológicas completas de Sigmund Freud. Rio de Janeiro: Imago, 1976

LACAN, Jacques. O Seminário, livro XI: Os quatro conceitos fundamentais da psicanálise. Rio de Janeiro: Jorge Zahar, 2008.

MAGNO, MD. A psicanálise, novamente: um pensamento para o século II da era freudiana. Rio de Janeiro: NovaMente Editora, 2004.

MAGNO, MD. Economia fundamental: metamorfoses da pulsão. Rio de Janeiro: Novamente, 2010.

MARTINS, André. Pulsão de Morte? Rio de janeiro: Editora UFRJ, 2009

NIETZSCHE, Friedrich. $A$ vontade de poder. Rio de Janeiro: Contraponto, 2008

NIETZSCHE, Friedrich. A genealogia da moral. São Paulo: Cia das Letras, 2009

NIETZSCHE, Friedrich. O Anticristo. São Paulo: Cia das Letras, 2007

NIETZSCHE, Friedrich. Além do Bem e do Mal. São Paulo: Cia das Letras, 2005

NIETZSCHE, Friedrich. Assim falava Zaratustra. São Paulo: Escala, s/d

SCHOPENHAUER, Artur. O Mundo como vontade e representação. Porto: Rés Editora, $\mathrm{s} / \mathrm{d}$ 